\title{
Pneumomediastinum: retrospective analysis of 19 cases and an innovation proposal in classification
}

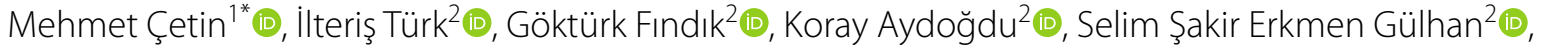

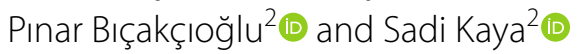

\begin{abstract}
Background: Guidelines to standardize treatment and follow-up strategies in pneumomediastinum cases are lacking. The aim of the study was to evaluate the etiology in pneumomediastinum cases and the results of treatment and follow-up.

Results: Nineteen patients with pneumomediastinum who were followed up in our clinic between 2015 and 2020 comprised the study population. Among the patients, 16 (84.2\%) were male, and the mean age was 31.15 years. The chief presenting complaints were chest pain and dyspnea. Pneumomediastinum was spontaneous in 15/19 patients (including spontaneous pneumomediastinum with an underlying pathology in 3/15), traumatic in 3/19, and iatrogenic in 1/19. Spontaneous pneumomediastinum without underlying pathology was seen in younger adults (mean age: 23 years). Surgical intervention in traumatic and iatrogenic pneumomediastinum cases was compared with spontaneous cases and no statistically significant difference was observed $(p=0.178)$. The mean hospital stay of all patients was 3.15 days. Only one patient had a recurrence and died, which was later determined to be a secondary spontaneous pneumomediastinum case.

Conclusion: Pneumomediastinum often occurs with an underlying pathology in advancing age and as spontaneous in younger patients. Therefore, "secondary spontaneous pneumomediastinum" subclass should be evaluated in the classification to facilitate to create a standard guideline and prevent overdiagnosis and overtreatment.
\end{abstract}

Keywords: Classification, Pneumomediastinum, Secondary spontaneous

\section{Introduction}

First reported by Hamman in 1939, pneumomediastinum (PM) is defined as the presence of free air in the mediastinum [1]. Secondary PM develops due to underlying esophageal and tracheal pathology or trauma, or history of surgical intervention, while primary/spontaneous PM etiology is unclear despite several contending theories [2].
Physicians generally prefer a conservative approach in primary/spontaneous PM, and patients are discharged after spontaneous resorption of mediastinal air, with rare recurrence. In contrast, surgical interventions including thoracotomy may be necessary, especially in complicated secondary PM cases, but there is no guideline for a standard approach in this regard [3].

In the present study, we share our clinical experience with PM cases in light of the literature.

\footnotetext{
*Correspondence: mehmetcetn@gmail.com

${ }^{1}$ Department of Thoracic Surgery, Omer Halisdemir University Training

and Research Hospital, Niğde, Turkey

Full list of author information is available at the end of the article
}

\section{Springer Open}

c) The Author(s) 2022. Open Access This article is licensed under a Creative Commons Attribution 4.0 International License, which permits use, sharing, adaptation, distribution and reproduction in any medium or format, as long as you give appropriate credit to the original author(s) and the source, provide a link to the Creative Commons licence, and indicate if changes were made. The images or other third party material in this article are included in the article's Creative Commons licence, unless indicated otherwise in a credit line to the material. If material is not included in the article's Creative Commons licence and your intended use is not permitted by statutory regulation or exceeds the permitted use, you will need to obtain permission directly from the copyright holder. To view a copy of this licence, visit http://creativecommons.org/licenses/by/4.0/. 


\section{Materials and methods}

Nineteen patients with PM who were followed up in our clinic between 2015 and 2020 were included in the retrospective study. We retrospectively analyzed the patients' data, including age, gender, presenting complaints, physical examination findings, comorbidities, CT images, diagnostic procedures such as bronchoscopy, esophagoscopy, follow-up periods, surgical interventions, complications, length of hospital stay, and recurrence.

We classified the PM patients who revealed no additional pathology in their examinations as primary/spontaneous PM, those with trauma history as traumatic, additional pathology as secondary spontaneous, and surgical intervention history such as transthoracic biopsy as iatrogenic.

Chi-square test was used to analyze differences between categorical variables. $P$ value below 0.05 was considered significant.

\section{Results}

Sixteen of the patients (84.2\%) were male and $3(15.8 \%)$ were female. The mean age was 31.15 years ( $\min : 20$, max: 83). The mean age of primary/spontaneous PM patients was 23 years (min: 20, max: 34). All patients underwent thoracic CT. The mean hospital stay of all patients was 3.15 days. Only one patient had a recurrence 2 weeks after discharge and died due to respiratory failure on the 4th day of his second hospital stay.

Table 1 shows the patients' data, including chief complaints, physical examination findings, comorbidities, additional radiological findings, interventional diagnostic procedures, treatment, surgical interventions, length of hospital stay, recurrence, and survival. Pretracheal fasciotomy or tube thoracostomy was decided according to the depth of the patient's respiratory distress and additional findings developed during follow-up and in addition to all these, since there is no standard approach guideline, at the discretion of the responsible physician. No case of tension pneumomediastinum or case requiring VATS or thoracotomy was detected.

Surgical intervention in traumatic and iatrogenic pneumomediastinum cases was compared with spontaneous cases and no statistically significant difference was observed ( $p=0.178, X^{2}=2.554$ ) (Table 2).

\section{Discussion}

The main finding in our study is that the mean age is quite low in patients without an underlying pathology in spontaneous pneumomediastinum cases (mean age: 23). In addition, an underlying disease was diagnosed in cases of spontaneous pneumomediatinum detected at an advanced age. There was no significant difference in the statistical analysis, since it was seen that proportionally more surgical intervention was needed in traumatic and iatrogenic pneumomediastinum cases $(p=0.178)$.

PM not occurring due to secondary causes such as iatrogenic, trauma, mechanical ventilation, and comorbidity is called primary (spontaneous) PM (Fig. 1) [4]. Primary $\mathrm{PM}$ is a very rare condition, primarily seen in young male individuals, with an incidence of 1:7000-1:45,000 [5]. The mean age of all patients in our study was 31.15 , but concerning only spontaneous PM, the mean age is 23 . This data suggests that the physician should consider secondary causes in PM patients as the age increases.

Although the etiology of primary PM is not clear, there is a theory that air with increased pressure dissects through the loose connective tissue and along the subcutaneous planes into the mediastinum [6]. In addition, the pathophysiologic process of PM known as the Macklin effect involves alveolar rupture, especially in blunt traumas, and as a result, air traveling along bronchovascular structures into the mediastinum [7]. Studies show that PM may be accompanied by pneumothorax if mediastinal gas migrates through the mediastinal pleura into the pleural space [4]. In the present study, we did not encounter pneumothorax among our spontaneous PM cases. However, we had a patient with iatrogenic PM and pneumothorax secondary to the interventional procedure (transthoracic biopsy).

In our study, secondary causes such as underlying malignancy and interstitial lung disease (ILD) were found especially in pneumomediastinum cases with advanced ages. In the classification of PM, the terms primary and spontaneous are used interchangeably. However, this usage falls short of explaining secondary spontaneous cases which are not traumatic or iatrogenic [4]. In parallel with the theories on the etiology of pneumomediastinum [6], it is supported that it is a triggering factor in advanced age spontaneous pneumomediastinum cases. In addition, when the literature was examined together with the small number of cases, it was seen in the study of Çelik et al. that 6 of 23 patients were over 40 years old, and secondary causes were observed in 5 of these patients (83\%). Malignancy was found in two patients, emphysematous lung in one patient, tuberculosis in one patient, and asthma in one patient [7]. In addition, although there are always case reports and small case series like our study, Alemu et al. evaluated 339 cases published in PubMed, in 57 patients (16.8\%) asthma, 19 (5.6\%) ILD, and 12 patients (3.5\%) found malignancy [8]. Since the age rates of the cases with secondary causes were not specified separately in this study, no additional interpretation of age could be made, but this study, in which all case reports were evaluated [8], strongly supports the need for a definition of secondary spontaneous 


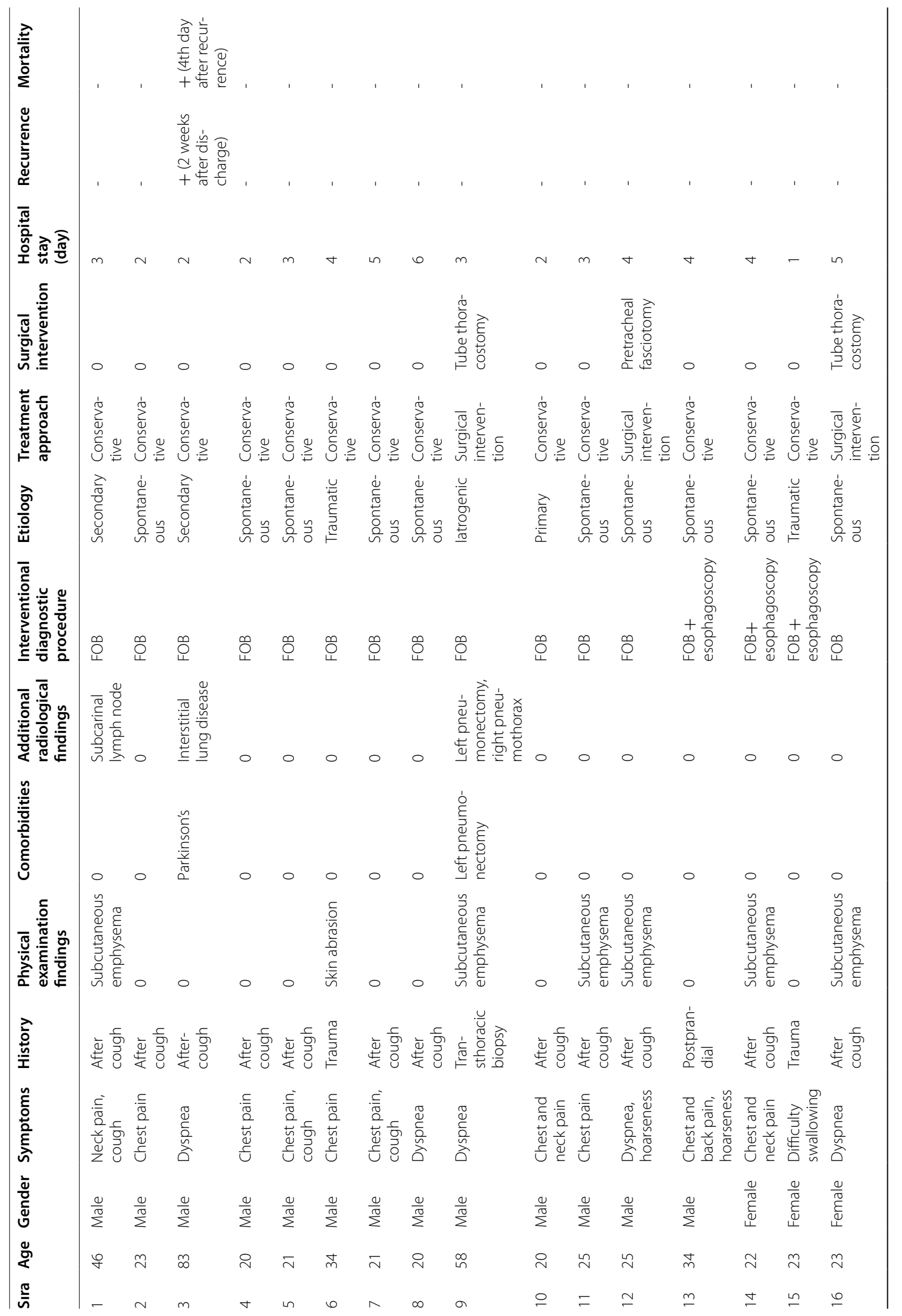




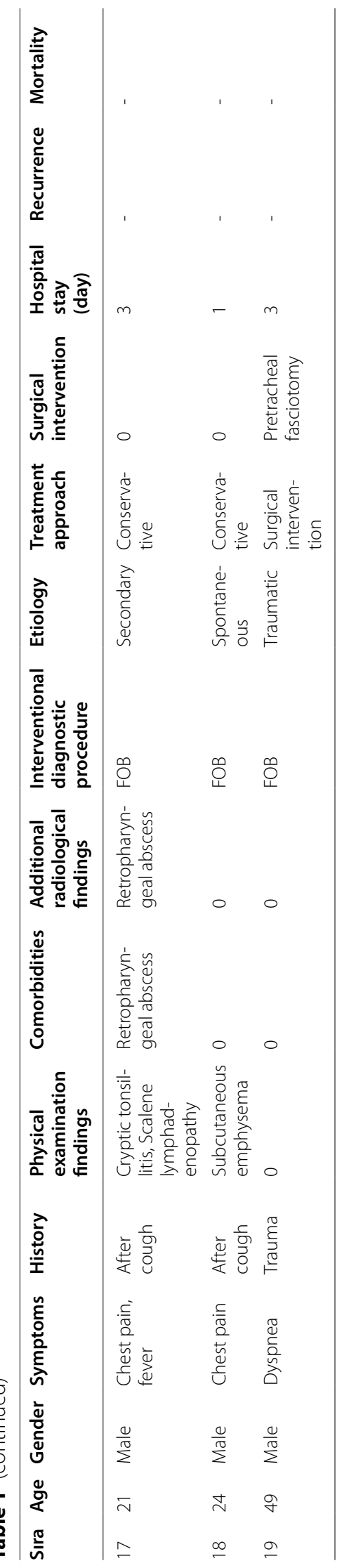


Table 2 Distribution of surgical intervention among groups in pneumomediastinum cases and chi-square analysis

\begin{tabular}{|c|c|c|c|c|c|c|}
\hline & \multicolumn{2}{|c|}{ Surgical intervention } & \multicolumn{2}{|c|}{ Conservative approach } & \multirow[b]{2}{*}{$\overline{x^{2}}$} & \multirow[b]{2}{*}{$p$} \\
\hline & $N$ & $\%$ & $N$ & $\%$ & & \\
\hline Spontaneous & 2 & 13.3 & 13 & 86.7 & 2.554 & 0.178 \\
\hline Not spontaneous & 2 & 50 & 2 & 50 & & \\
\hline
\end{tabular}

pneumomediastinum. As in the classification of pneumothorax [9], it may be viable to classify the cases, especially young adults ones, in which no underlying pathology is detected, as "primary spontaneous PM," and the cases that occur spontaneously but are later linked to a detected pathology such as malignancy or Boerhaave syndrome, as "secondary spontaneous PM." In addition, classifying other cases as acquired, traumatic, or iatrogenic would be further explanatory.

In our study, the most common complaints were chest pain (11/19) and dyspnea (6/19) after coughing (14/19). In addition, subcutaneous emphysema was palpated in PM in 7/19 patients. While bronchoscopy was performed in all patients, including esophagoscopy in 3 patients, tube thoracostomy was required in 2 patients and pretracheal fasciotomy was required in 2 patients. In addition, mortality was observed in 1 patient.

The chief complaints in PM patients are acute dyspnea and chest pain, mainly extending from the retrosternal region to the neck, in addition to less frequent symptoms of hoarse voice, difficulty swallowing, sore throat, and cough [10]. Spontaneous PM is mostly observed in younger patients whose mediastinal tissues are loose and flaccid, in contrast to elderly individuals with age-related pulmonary fibrosis, preventing air movement into the mediastinum. Therefore, PM should be considered in young patients presenting with acute dyspnea, chest pain, or both [11]. Besides, in malignant PM, which can cause compression of organs, patients may present with shock, accompanied by loss of consciousness.

On physical examination, subcutaneous emphysema can be palpated, especially in cases with progressed air leak [11]. In addition, Hamman's sign, a crunching or clicking noise, can be heard during systole on cardiac auscultation [1]. Since higher noise intensity is typical in malignant PM, cervical venous engorgement due to anomalous return, hypotension, tachycardia, tachypnea, or pulsus paradoxus may manifest.

Although chest X-ray is usually the first examination, thoracic CT is the gold standard in diagnosing PM since it shows the air density and reveals the underlying organ pathology (Fig. 2) [4]. In our clinic, we prefer thoracic CT at initial hospital admission in all patients. We detected severe ILD in an 83-year-old patient on thoracic CT. PM, which is generally benign in young individuals, should be assessed carefully in elderly patients since it may be due to secondary causes.

In addition to routine bronchoscopy, esophagoscopy is not performed in all patients in our clinic in case of findings not involving the gastrointestinal tract. In one of our cases, we diagnosed a 46-year-old male patient with small cell lung cancer as a result of a biopsy taken from the carinal area with bronchoscopy, together with the suspicion in the CT findings. In the presence of symptoms such as vomiting and hemoptysis or clinical suspicion that may radiologically explain PM etiology, advanced tests such as bronchoscopy and esophagoscopy can be performed. Oesophagography with opaque material may also be used if perforation is suspected [12].

While most of the patients followed up in our clinic were followed with a conservative approach including antibiotic therapy, interventional procedure was performed in only 4 patients. In addition, we did not have any patient who needed exploration with video-assisted thoracoscopic surgery (VATS) or thoracotomy. A conservative approach is generally preferred in cases without underlying disease (primary/spontaneous PM). Patients should be monitored for at least $24 \mathrm{~h}$, and infection and vital sign parameters should be assessed under analgesic treatment and oxygen support [8]. Although prophylactic antibiotic therapy is not typically recommended [13], there are also publications recommending routine antibiotic therapy despite the risk of developing mediastinitis [10]. In patients presenting with respiratory noise (i.e., a clinical picture with progressive dyspnea, pain, hoarseness, tamponade) and a large, progressing air density, the physician can perform decompression using skin incision, pretracheal fasciotomy, tube thoracostomy, and, in emergency cases, VATS/ thoracotomy [8]. Tube thoracostomy is generally adequate, especially during follow-up when the mediastinal air with increased pressure dissects through the mediastinal pleura, causing pneumothorax. Unfortunately, there is no standard guideline for the interventional approach, and the decision depends on the patient's clinical picture [14]. Despite our small population size, this suggests that traumatic PM is likely to have a more aggressive clinical course.

The patients can be discharged if no additional pathology is present and no increase in the volume of pneumomediastinum is observed on chest X-rays. 


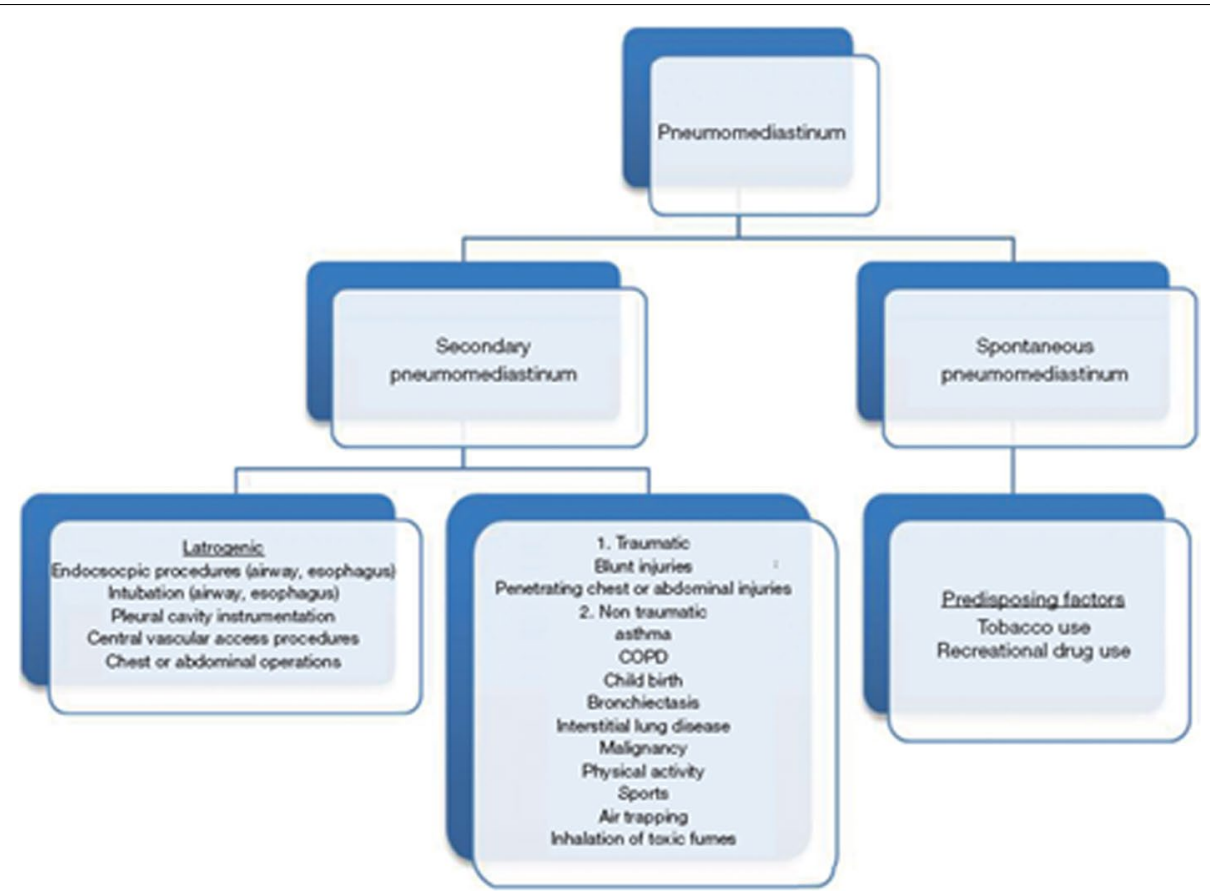

Fig. 1 Classification of pneumomediastinum

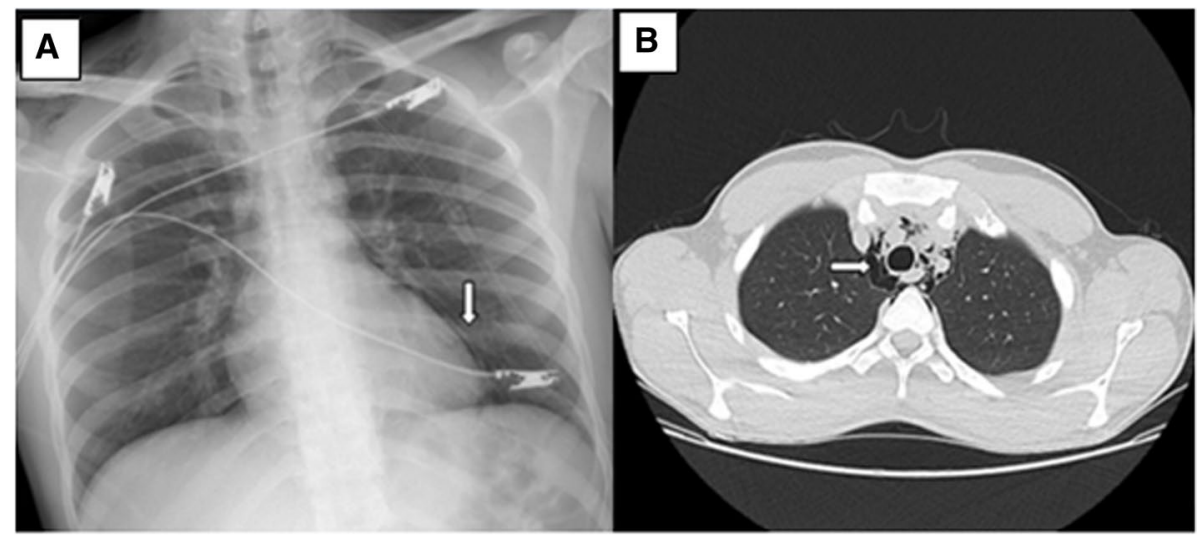

Fig. 2 A. Pneumomediastinum chest $X$-ray image; B. Pneumomediastinum thorax BT image

Although recurrence is not common, patients should be followed up carefully, and the underlying pathology should be thoroughly investigated in case of frequent recurrences [13].

The valuable aspect of our study is that despite the small number of patients, it includes all subclasses in the etiology of PM, supporting the place of age in the etiology. In addition, when evaluated together with the study [8] examining 339 case reports published in the literature until 2018, the curiosity about the age of secondary spontaneous pneumomediastinum patients emphasized in the same study constitutes the value of this study. In addition, the most important limitation is the small number of patients.

To conclude, PM generally occurs secondary to underlying conditions such as malignancy and ILD in advanced ages and spontaneously in younger adults. Therefore, a "secondary spontaneous PM" definition is necessary along with a standard guideline for accuracy in diagnosis and management, preventing defensive medicine leading to overdiagnosis and overtreatment for primary spontaneous PM. 


\section{Abbreviations}

CT: Computed tomography; ILD: Interstitial lung disease; PM:

Pneumomediastinum.

\section{Code availability}

Not applicable

\section{Authors' contributions}

Dr. Çetin designed the study together with Dr. Türk. Dr. Fındık contributed to the organization and planning of the study. Other authors assisted in editing. The English of the manuscript is checked by a native English speaker. The author(s) read and approved the final manuscript.

\section{Funding}

This research received no specific grant from any funding agency in the public, commercial, or not-for-profit sectors

\section{Availability of data and materials}

Available

\section{Declarations}

\section{Ethics approval and consent to participate}

Local ethical committee approval was taken for the study. Consent was not obtained from the participants as it was a retrospective study.

\section{Consent for publication}

Consent for publication was taken from all authors.

\section{Competing interests}

There is no potential conflict of interest to declare.

\section{Author details}

'Department of Thoracic Surgery, Omer Halisdemir University Training and Research Hospital, Niğde, Turkey. ${ }^{2}$ Department of Thoracic Surgery, Ataturk Chest Disease and Thoracic Surgery Training and Research Hospital, Ankara, Turkey.

Received: 5 October 2021 Accepted: 9 December 2021

Published online: 06 January 2022

\section{References}

1. Hamman L (1914) Spontaneous pneumothorax. Trans Am Climatol Clin Assoc 30:273-289

2. Macia I, Moya J, Ramos R et al (2007) Spontaneous pneumomediastinum: 41 cases. Eur J Cardio-Thoracic Surg 31:1110-1114. https://doi.org/10. 1016/j.ejcts.2007.03.008

3. Dajer-Fadel WL, Argüero-Sánchez R, Ibarra-Pérez C, Navarro-Reynoso FP (2014) Systematic review of spontaneous pneumomediastinum: a survey of 22 years' data. Asian Cardiovasc Thorac Ann 22:997-1002. https://doi. org/10.1177/0218492313504091

4. Kouritas VK, Papagiannopoulos K, Lazaridis G et al (2015) Pneumomediastinum. J Thorac Dis 7:S44-S49. https://doi.org/10.3978/j.issn.2072-1439. 2015.01.11

5. Iyer VN, Joshi AY, Ryu JH (2009) Spontaneous pneumomediastinum: analysis of 62 consecutive adult patients. Mayo Clin Proc 84:417-421. https://doi.org/10.1016/S0025-6196(11)60560-0

6. Macklin MT, Macklin CC (1944) Malignant interstitial emphysema of the lungs and mediastinum as an important occult complication in many respiratory diseases and other conditions. Medicine (Baltimore) 23:281-358. https://doi.org/10.1097/00005792-194412000-00001

7. Çelik B, Pirzirenli MG, Büyükkarabacak YB et al (2021) Clinical and radiological characteristics of patients treated with the diagnosis of spontaneous pneumomediastinum. Curr Thorac Surg 6:1. https://doi.org/10.26663/cts. 2021.0001
8. Alemu BN, Yeheyis ET, Tiruneh AG (2021) Spontaneous primary pneumomediastinum: is it always benign? J Med Case Rep 15(1):157. https://doi. org/10.1186/s13256-021-02701-z

9. Costumbrado J, Ghassemzadeh S (2021) Spontaneous pneumothorax. StatPearls Publishing, In StatPearls

10. Perna V, Vilà E, Guelbenzu JJ, Amat I (2010) Pneumomediastinum: is this really a benign entity? When it can be considered as spontaneous? Our experience in 47 adult patients. Eur J Cardio-Thoracic Surg 37:573-575. https://doi.org/10.1016/j.ejcts.2009.08.002

11. Dionísio P, Martins L, Moreira S et al (2017) Spontaneous pneumomediastinum: experience in 18 patients during the last 12 years. J Bras Pneumol 43:101-105. https://doi.org/10.1590/s1806-375620160000000 52

12. Talwar A, Esquire A, Sahni S et al (2013) Spontaneous pneumomediastinum: Time for consensus. N Am J Med Sci 5:460. https://doi.org/10.4103/ 1947-2714.117296

13. Al-Mufarrej F, Badar J, Gharagozloo F et al (2008) Spontaneous pneumomediastinum: diagnostic and therapeutic interventions. J Cardiothorac Surg 3:59. https://doi.org/10.1186/1749-8090-3-59

14. Karabacak K (2013) Recurrent spontaneous pneumomediastinum and pneumorrhachis accompanied by Raynaud's phenomenon. Turkish J Thorac Cardiovasc Surg 21:1086-1089. https://doi.org/10.5606/tgkdc. dergisi.2013.6880

\section{Publisher's Note}

Springer Nature remains neutral with regard to jurisdictional claims in published maps and institutional affiliations.

\section{Submit your manuscript to a SpringerOpen ${ }^{\circ}$ journal and benefit from:}

- Convenient online submission

- Rigorous peer review

- Open access: articles freely available online

- High visibility within the field

- Retaining the copyright to your article

Submit your next manuscript at $\boldsymbol{\nabla}$ springeropen.com 